\title{
Limited Knowledge of Acetaminophen in Patients with Liver Disease
}

\author{
Sammy Saab*1,2 ${ }^{2}$ Peter G. Konyn², Matthew R. Viramontes ${ }^{2}$, Melissa A. Jimenez ${ }^{2}$ \\ Jonathan F. Grotts ${ }^{3}$, Wally Hamidzadah², Veronica P. Dang ${ }^{2}$, Negin L. Esmailzadeh ${ }^{2}$ \\ Gina Choi ${ }^{1,2}$, Francisco A. Durazo ${ }^{1,2}$, Mohamed M. El-Kabany ${ }^{1,2}$, Steven-Huy B. Han ${ }^{1,2}$ \\ and Myron J. Tong ${ }^{2,4}$
}

\begin{abstract}
${ }^{1}$ Department of Medicine, the University of California at Los Angeles, Los Angeles, CA, USA; ${ }^{2}$ Department of Surgery, the University of California at Los Angeles, Los Angeles, CA, USA; ${ }^{3}$ Department of Biostatistics, the University of California at Los Angeles, Los Angeles, CA, USA; ${ }^{4}$ California and Huntington Medical Research Institutes, Pasadena, CA, USA
\end{abstract}

\begin{abstract}
Background and Aims: Unintentional acetaminophen overdose remains the leading cause of acute liver failure in the United States. Patients with underlying liver disease are at higher risk of poor outcomes from acetaminophen overdose. Limited knowledge of acetaminophen may be a preventable contributor to elevated rates of overdose and thus acute liver failure. The purpose of this study is to assess knowledge of acetaminophen dosing and presence of acetaminophen in common combination products in patients with liver disease. Methods: We performed a cross-sectional study of patients with liver disease at the Pfleger Liver Institute at the University of California, Los Angeles between June 2015 and August 2016. Patients completed a demographic questionnaire and an acetaminophen knowledge survey. Additional information was obtained from the medical record. Results: Of 401 patients with liver disease, $30(15.7 \%)$ were able to correctly identify that people without liver disease can safely take up to $4 \mathrm{~g} /$ day of acetaminophen. The majority of patients $(79.9 \%-$ $86.8 \%$ ) did not know that Norco ${ }^{\circledR}$ (hydrocone/acetaminophen), Vicodin $\AA$ (hydrocone/acetaminophen) and Percocet $\AA$ (oxycodone/acetaminophen) contained acetaminophen. Only $45.3 \%$ of the patients knew that Tylenol $\mathbb{R}$ \#3 contained acetaminophen.Conclusions: We conclude that patients with liver disease have critically low levels of knowledge of acetaminophen, putting them at risk both of acetaminophen overdose, as well as undermedication, and inadequate management of chronic pain. We recommend an increase in education efforts regarding acetaminophen dosage and its safety in the setting of liver disease. Increasing education for those at risk of low acetaminophen knowledge is essential to minimizing acetaminophen overdose rates and optimizing pain management.
\end{abstract}

Keywords: Acetaminophen; Pain management; Cirrhosis.

Abbreviations: OR, odds ratio; CI, 95\% confidence interval; NSAID, nonsteroidal anti-inflammatory drug; FDA, Federal Drug Administration; IQR, interquartile range; N/A, not answered; PPO, preferred-provider organization; HMO, health maintenance organization; GHPP, genetically handicapped person's program. Received: 30 September 2016; Revised: 02 December 2016; Accepted: 22 December 2016

DOI: $10.14218 / \mathrm{JCTH} .2016 .00049$.

* Correspondence to: Sammy Saab, Pfleger Liver Institute, UCLA Medical Center, 200 Medical Plaza, Suite 214, Los Angeles, CA 90095, USA. Tel: +1-310-2066705, Fax: +1-310-206-4197, E-mail: SSaab@mednet.ucla.edu
(C) 2016 The Second Affiliated Hospital of Chongqing Medical University. Published by XIA \& HE Publishing Inc. All rights reserved.

\section{Introduction}

Acetaminophen is the most commonly used analgesic in the United States. Its use is indicated in a wide range of ailments, such as osteoarthritis, migraine headaches and fever. ${ }^{1-3}$ Part of its attractiveness is that it is inexpensive, well tolerated and readily available in oral formulations. ${ }^{4}$ In 2008 alone, there were 24.6 billion doses consumed in the United States. ${ }^{5}$ Tylenol $\AA$ can be consumed alone, or as part of an analgesic combination. While this drug is of benefit to many, it also comes with many risks, as acetaminophen is the most common cause of drug-induced liver failure in the United States. ${ }^{6}$

Approximately 60,000 people are hospitalized each year in the United States for acetaminophen overdose complications. ${ }^{7}$ The percentage of these individuals who receive a diagnosis of acetaminophen-induced liver toxicity has risen from $6 \%$ in 1998 to $13 \%$ in $2011 .^{6}$ In most individuals, the overdose is accidental. $6,8,9$ These individuals unintentionally consume excessive acetaminophen due to a lack of knowledge of the maximal safe dose of acetaminophen itself, or lack of awareness of the quantity of common analgesics, which contain acetaminophen. ${ }^{10}$ Certain patient scenarios accompanying acetaminophen overdose are linked to poorer outcomes, such as chronic alcohol consumption, unintentional overdose, and underlying liver disease. ${ }^{11-16}$

In patients with chronic liver disease, the prevalence of unintentional acetaminophen overdose is disproportionately high, compared to those without known liver disease. ${ }^{12,17}$ As patients with cirrhosis may have impaired hepatic function to metabolize certain drugs, ${ }^{18}$ the consumption of a dose of acetaminophen lower than recommended daily maximum might lead to acute liver injury. ${ }^{19}$ Providing safe and effective analgesia to patients with cirrhosis can be a clinical challenge. Despite the increased risk of overdose toxicity, acetaminophen is still considered the safest analgesic for patients with liver cirrhosis. ${ }^{20,21}$ Acetaminophen is preferred over nonsteroidal anti-inflammatory drugs (NSAIDs) in patients with liver disease because of the risk of nephrotoxicity, gastrointestinal 
toxicity and platelet impairment associated with medications in that class. ${ }^{20,22-25}$

While not much is known specifically about the safety of acetaminophen use in patients with liver disease, experts recommend a maximum daily dose of $4 \mathrm{~g}$ /day for patients with hepatic impairment. ${ }^{20,22,26,27}$ These recommendations are based on several randomized trials and observational studies whose outcome were changes in findings of liverassociated tests and/or worsening liver function. ${ }^{28-33}$ In 2009, the US Food and Drug Administration (FDA) advisory committee issued a relabeling of acetaminophen-containing products to better inform patients with liver disease about a potential risk of further liver injury. ${ }^{34}$ However, patients' understanding of acetaminophen dose after relabeling of acetaminophen containing products has not been studied in patients with liver disease. Our hypothesis is that patients with known liver disease have inadequate knowledge about daily acetaminophen dosage recommendations and common pain medications that contain acetaminophen.

\section{Methods}

\section{Study subjects}

This observational, cross-sectional study included adult patients with liver disease who were seen for follow-up at the Pfleger Liver Institute, University of California, Los Angeles. The study was conducted from June 2015 to August 2016. The surveys and informed consent processes were administered in both English and Spanish, and translation services were provided for patients whose native language was neither English nor Spanish.

All eligible patients seen in the Pfleger Liver Institute were invited to participate in the study by investigators during their visit at the clinic. Following a short verbal explanation of the study, participants were administered questionnaires as described below. Participation in the study was voluntary and there was no compensation offered. The University of California, Los Angeles Institutional Review Board approved the study.

The medical records of all study participants were accessed in order to obtain information about the patients' insurance type, liver disease categorization, and whether or not they have a diagnosis of cirrhosis. Liver disease diagnosis was categorized as hepatitis $B$, autoimmune hepatitis, hepatocellular cancer, hepatitis C, non-alcoholic fatty liver disease, alcoholic hepatitis, acetaminophen hepatotoxicity, or other.

\section{Questionnaires}

Each participant completed one self-administered questionnaire, which was separated into a section for demographics, a section for patient preferences for education on medicine, and a section that assessed their knowledge of appropriate Tylenol ${ }^{\circledR}$ use for patients with liver disease. Questions were written with an $8^{\text {th }}$ grade reading level as the intended complexity.

The demographics section involved 9 questions including inquiries regarding patient age, gender identity, ethnicity, education, income, employment status, and how long the patient had known about their liver disease. The knowledge assessment consisted of 13 questions including whether or not Norco, Vicodin, Percocet, or Tylenol ${ }^{\circledR}$ \#3 have acetaminophen, the maximum tablets of each strength of the previously mentioned analgesic that can be safely taken daily, and the maximum daily amount of acetaminophen that can be safely taken by patients with and without liver cirrhosis.

\section{Statistics}

Responses to Tylenol ${ }^{\circledR}$ knowledge survey questions were formatted for statistical analysis as either correct or incorrect. Correct answers to survey questions were based on medication package inserts. ${ }^{35-38}$ Answers marked as 'not sure' were coded as incorrect. Answers left blank by the participant were coded as incorrect. Discrete variables were presented as the number of participants belonging to that group, followed by the percentage equivalent in parenthesis. Continuous data were presented as a median with interquartile range (IQR) in parenthesis, unless otherwise specified. A t-test or Wilcoxon rank sum test was used to compare continuous variables based on distribution of data and a Fisher's exact test or chisquare test was used to compare discrete data. All tests were two-sided and a $p$-value below 0.05 was considered statistically significant. Some variables were formatted for the multivariable model. Age, education and pain medication use within 6 months were dichotomized and employment status was combined with amount worked. Variables were entered into the multivariable model if they were significant at the 0.10 level on univariate analysis. The multivariable model was a logistic regression.

\section{Results}

\section{Demographics}

A total of 401 patients with liver disease were enrolled over a period of 15 months. The demographic characteristics of the study population are represented in Table 1 . The majority of patients were male (53.4\%) and their median (IQR) age was 60 (51-67) years. Most patients were non-Hispanic white $(39.7 \%)$ and had at least college-level education. Most patients had yearly income levels of less than $\$ 50,000$. Preferred Provider Organization was the common insurance utilized by the patients.

The patients' median (IQR) length of time since the diagnosis of liver disease was made was 7 (2-15) years. The most common diagnoses were hepatitis C (42.6\%), hepatitis B (23.9\%) and non-alcoholic fatty liver disease $(15.7 \%)$. Approximately two-thirds of patients had underlying cirrhosis. Less than $20 \%$ of patients were new patients to our Liver Institute, and less than half of all the patients in our study were able to reveal a caregiver.

\section{Patient preferences for health and medication information}

The majority $(59.6 \%)$ of patients had taken pain medication in the last 6 months. Participant responses to questions regarding preferences for health and pain medicine use information is shown in Table 2. In particular, we queried both the source and quality of where patients obtain information regarding over-the-counter medicines. Moreover, we stratified the data according to whether or not the respondents were Hispanic.

The majority of patients $(60.5 \%)$ claimed that they speak with a physician before choosing an over-the-counter medication. However, Hispanic patients were also less likely to 
Saab S. et al: Acetaminophen and liver disease

Table 1. Demographic characteristics of 401 patients with liver disease

\begin{tabular}{|c|c|}
\hline Characteristic & $\begin{array}{l}\text { Number of } \\
\text { Responses }\end{array}$ \\
\hline \multicolumn{2}{|l|}{ Gender identity } \\
\hline Female & $187(46.6 \%)$ \\
\hline Male & $214(53.4 \%)$ \\
\hline \multicolumn{2}{|l|}{ Ethnicity } \\
\hline Non-Hispanic White & $159(39.7 \%)$ \\
\hline Hispanic White & $123(30.7 \%)$ \\
\hline African American & $26(6.5 \%)$ \\
\hline Asian & $64(16 \%)$ \\
\hline Other & $39(9.7 \%)$ \\
\hline \multicolumn{2}{|l|}{ Education } \\
\hline High school or less & $135(33.7 \%)$ \\
\hline Some college or more & $266(66.3 \%)$ \\
\hline \multicolumn{2}{|l|}{ Estimated Annual Income } \\
\hline$<\$ 50,000$ & $167(41.6 \%)$ \\
\hline$\$ 50,000-100,000$ & $120(29.9 \%)$ \\
\hline$>\$ 100,000$ & $64(16 \%)$ \\
\hline $\mathrm{N} / \mathrm{A}$ & $50(12.5 \%)$ \\
\hline \multicolumn{2}{|l|}{ Employment Status } \\
\hline Yes & $258(64.3 \%)$ \\
\hline No & $143(35.7 \%)$ \\
\hline \multicolumn{2}{|l|}{ If Employed, Hours Worked per Week } \\
\hline $1-20$ & $23(16.2 \%)$ \\
\hline $21-40$ & $46(32.4 \%)$ \\
\hline$>40$ & $71(50 \%)$ \\
\hline N/A & $2(1.4 \%)$ \\
\hline \multicolumn{2}{|l|}{ Insurance type } \\
\hline PPO & $165(41.1 \%)$ \\
\hline Free for Service Medical/MediCal HMO & $50(12.5 \%)$ \\
\hline GHPP/Non-Medical HMO & $23(6.7 \%)$ \\
\hline No Insurance/Self-pay & $4(1 \%)$ \\
\hline Medicare & $156(38.9 \%)$ \\
\hline Other & $10(2.5 \%)$ \\
\hline \multicolumn{2}{|l|}{ Etiology of Disease } \\
\hline Hepatitis B & $96(23.9 \%)$ \\
\hline Autoimmune Hepatitis & $25(6.2 \%)$ \\
\hline Hepatocellular Cancer & $35(8.7 \%)$ \\
\hline Hepatitis C & $171(42.6 \%)$ \\
\hline $\begin{array}{l}\text { Non-Alcoholic Fatty } \\
\text { Liver Disease }\end{array}$ & $63(15.7 \%)$ \\
\hline Acetaminophen Hepatotoxicity & $0(0 \%)$ \\
\hline Other & $61(15.2 \%)$ \\
\hline \multicolumn{2}{|l|}{ Presence of Cirrhosis } \\
\hline Yes & $255(63.6 \%)$ \\
\hline No & $146(36.4 \%)$ \\
\hline
\end{tabular}

Table 1. (continued)

\begin{tabular}{ll}
\hline Characteristic & $\begin{array}{l}\text { Number of } \\
\text { Responses }\end{array}$ \\
\hline $\begin{array}{l}\text { Does the Patient Have a Caregiver? } \\
\text { Yes }\end{array}$ & $170(42.4 \%)$ \\
No & $231(57.6 \%)$ \\
Visit Type & \\
New & $73(18.2 \%)$ \\
Follow-up & $328(81.8 \%)$
\end{tabular}

Abbreviations: N/A, Not answered; PPO, Preferred provider organization; HMO, Health maintenance organization; GHPP, Genetically handicapped persons program.

say they speak with a physician before choosing an overthe-counter medication $(p=0.015)$. Hispanics were less likely than the Non-Hispanics to consider their Physician ( $p=0.015)$ or Nurse $(p=0.01)$ as a valuable and trustworthy source of information about health and medicine use.

\section{Patient knowledge of common prescription medications containing acetaminophen and maximum recommended daily dose of acetaminophen}

Thirty $(7.5 \%)$ of the participants were able to correctly identify that the recommended maximum daily dose of acetaminophen that a person without liver disease can safely take is $<4 \mathrm{~g} /$ day (Fig. 1 ). Few patients knew that the maximum acetaminophen dose in the setting of cirrhosis was less than $3 \mathrm{~g}$ per day; there were no differences in knowledge between cirrhotic and non-cirrhotic patients (Fig. 2). Approximately $20 \%$ of our study participants felt that no amount of acetaminophen was safe (Fig. 2).

Most patients were unaware commonly prescribed pain medications contained acetaminophen. Specifically, the majority of patients $(79.9 \%-86.8 \%)$ did not know that Norco $\AA$ (hydrocodone/acetaminophen), Vicodin ${ }^{\circledR}$ (hydroco-

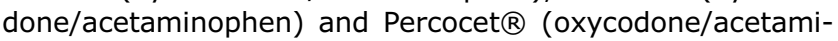
nophen) contained acetaminophen. Only $45.3 \%$ knew that Tylenol ${ }^{\circ}$ \#3 contained acetaminophen. The independent predictors for correctly answering if prescription pain medication contained acetaminophen are shown in Table 3 . The most common predictor of correctly identifying the presence of acetaminophen in the different pain medication combinations was the patient use of pain medications in previous 6 months.

\section{Discussion}

The results of this study indicate that knowledge of acetaminophen among patients with liver disease is limited, which may explain why unintentional acetaminophen overdose makes up such a large portion of cases of acute liver failure. ${ }^{10}$ Low levels of acetaminophen knowledge found in this population also poses a potential problem of under-medication and inadequate pain management in patients with liver disease. There currently lacks sufficient data describing prevalence and effectiveness in managing pain in patients with liver disease.

Previously established predictors of health literacy include location of residence, household income, highest level of 


\begin{tabular}{|c|c|c|c|c|}
\hline \multirow[b]{2}{*}{ Question } & \multicolumn{3}{|c|}{ Number of Responses } & \multirow[b]{2}{*}{ p-value } \\
\hline & $\begin{array}{l}\text { All Participants } \\
(\mathrm{n}=401)\end{array}$ & $\begin{array}{l}\text { Non-Hispanics } \\
(\mathrm{n}=278)\end{array}$ & $\begin{array}{l}\text { Hispanics } \\
(n=123)\end{array}$ & \\
\hline \multicolumn{5}{|c|}{ Who do you speak with before choosing an over-the-counter medicine? } \\
\hline Pharmacist & $146(36.4 \%)$ & $93(33.5 \%)$ & $53(43.1 \%)$ & 0.072 \\
\hline Physician & $243(60.5 \%)$ & $180(64.7 \%)$ & $63(51.2 \%)$ & 0.015 \\
\hline Friends/family & $73(18.2 \%)$ & $51(18.3 \%)$ & $22(17.9 \%)$ & 1 \\
\hline Other medical personnel & $20(4 \%)$ & $14(5 \%)$ & $6(4.9 \%)$ & 1 \\
\hline $\begin{array}{l}\text { Rarely or never talk with above people } \\
\text { before choosing an over the counter } \\
\text { medicine }\end{array}$ & $46(11.5 \%)$ & $35(12.6 \%)$ & $11(8.9 \%)$ & 0.314 \\
\hline No response & $6(1.5 \%)$ & $5(1.8 \%)$ & $1(0.8 \%)$ & 0.671 \\
\hline \multicolumn{5}{|c|}{ Who do you feel are valuable and trustworthy sources of information about health and medicine? } \\
\hline Physician & $351(87.6 \%)$ & $255(91.7 \%)$ & $96(78 \%)$ & $<0.001$ \\
\hline Pharmacist & $157(39.2 \%)$ & $117(42.1 \%)$ & $40(32.5 \%)$ & 0.076 \\
\hline Nurse & $91(22.7 \%)$ & $73(26.3 \%)$ & $18(14.6 \%)$ & 0.01 \\
\hline Other medical personnel & $44(11 \%)$ & $22(7.9 \%)$ & $22(7.9 \%)$ & 0.197 \\
\hline Advertising & $3(7.5 \%)$ & $2(0.7 \%)$ & $1(0.8 \%)$ & 1 \\
\hline Friends/family & $51(12.8 \%)$ & $37(13.3 \%)$ & $14(11.4 \%)$ & 0.63 \\
\hline No response & $10(2.5 \%)$ & $4(1.4 \%)$ & $6(4.9 \%)$ & 0.075 \\
\hline
\end{tabular}

education, ethnic background, and level of English proficiency, ${ }^{39}$ and others have noted a direct correlation between health literacy with health outcomes. ${ }^{40}$ Some studies have found females in a population to exhibit significantly higher health literacy than males. ${ }^{41}$ Previous studies assessing acetaminophen knowledge have found interesting gender differences as well, including that females are more likely to inform their doctor of current acetaminophen use and more likely to know the acetaminophen content of medications and the maximum recommended daily dose of acetaminophen. ${ }^{42,43}$ Female participants in this study were more likely to know that Vicodin $\AA$ and Percocet $\AA$ contained acetaminophen than males, which fits with the general findings that women tend to have higher health literacy than men. This observation is important because, despite increased health literacy, women suffer disproportionately low quality of life with liver cirrhosis compared to men $^{44}$ and tend to have their pain taken less seriously by health care professionals. ${ }^{45}$ Regarding preferences for sources of health information, our results are in

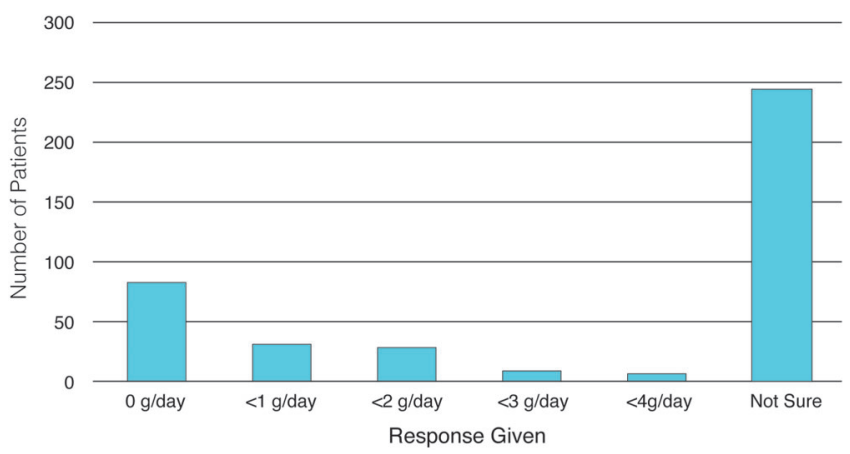

Fig. 1. Patients knowledge of maximum safe dose of Tylenol $\circledast$ for patients without liver cirrhosis. concordance with previous studies, which have demonstrated lower levels of trust in health care professionals among Hispanic patients compared to non-Hispanic white patients. ${ }^{46}$ Levels of trust in Hispanic patients have also been shown to differ based on levels of English proficiency. ${ }^{47}$ More research is necessary to better understand how gender and ethnicity inform a patient's experience with pain and chronic liver disease and how some of these disparities can be addressed.

There was a common theme that patients believed acetaminophen to be inherently toxic to the liver, and therefore contraindicated in liver disease. These perceptions were reflected in the fact that $230(57.4 \%)$ of our participants believed that patients with liver disease could not safely take any acetaminophen. Furthermore, of the 230 patients that provided an answer other than 'not sure' for the Tylenol ${ }^{\circledR} \# 3$ dosing questions, $78 \%$ reported believing that the maximum safe dose of Tylenol ${ }^{\circledR}$ \#3 was the same for both the $300 \mathrm{mg} /$ $30 \mathrm{mg}$ and the $300 \mathrm{mg} / 60 \mathrm{mg}$ strength. Indicating a shared perception that acetaminophen is the component of the

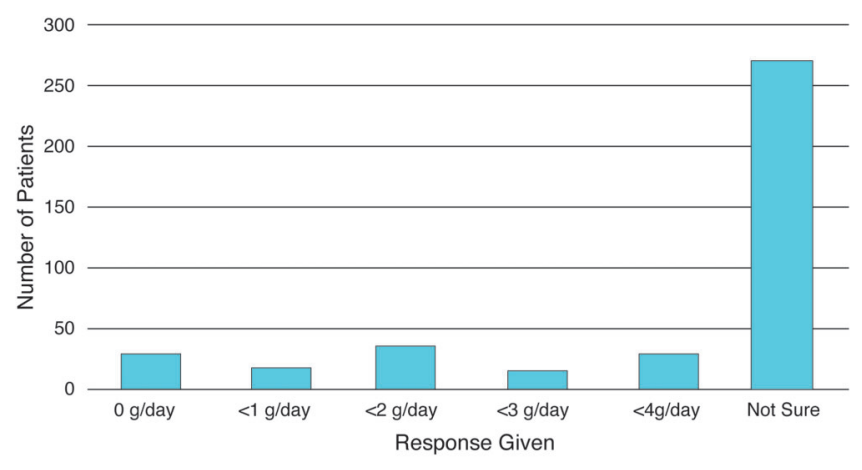

Fig. 2. Patients knowledge of maximum safe dose of Tylenol® for patients with liver cirrhosis. 


\begin{tabular}{|c|c|c|c|}
\hline Independent Predictor & Odds Ratio & $\begin{array}{l}95 \% \text { Confidence } \\
\text { Interval }\end{array}$ & p-value \\
\hline \multicolumn{4}{|l|}{ Does the prescription drug $N O R C O \AA$ contain Tylenol $($ ? } \\
\hline $\begin{array}{l}\text { Rarely or never talking with someone before } \\
\text { choosing an over-the-counter medication }\end{array}$ & 2.757 & 1.364 to 5.574 & 0.006 \\
\hline Taking pain medication within the past 6 months & 3.968 & 1.994 to 7.895 & $<0.001$ \\
\hline \multicolumn{4}{|l|}{ Does the prescription drug VICODIN® } \\
\hline Age $\geq 60$ & 0.455 & 0.26 to 0.797 & 0.005 \\
\hline Male gender & 0.565 & 0.318 to 1.005 & 0.049 \\
\hline Taking pain medication within the past 6 months & 4.409 & 2.177 to 8.93 & $<0.001$ \\
\hline \multicolumn{4}{|c|}{ 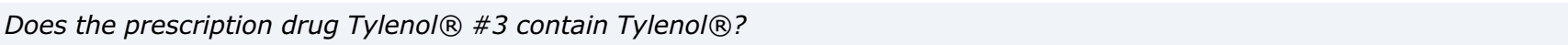 } \\
\hline Age $\geq 60$ & 0.427 & 0.243 to 0.751 & 0.003 \\
\hline $\begin{array}{l}\text { Trusting physicians as a source of information on } \\
\text { health and medicine use }\end{array}$ & 3.135 & 0.898 to 10.943 & 0.043 \\
\hline Taking pain medication within the past 6 months & 4.147 & 2.059 to 8.353 & $<0.001$ \\
\hline \multicolumn{4}{|c|}{ Does the prescription drug PERCOCET® contain Tylenolß? } \\
\hline Age $\geq 60$ & 0.441 & 0.25 to 0.781 & 0.004 \\
\hline Male gender & 0.558 & 0.313 to 0.995 & 0.045 \\
\hline Taking pain medication within the past 6 months & 4.446 & 2.187 to 9.037 & $<0.001$ \\
\hline
\end{tabular}

medication that prevents the safe consumption of a higher amount of tablets. Among 23 patients that provided two or more responses other than 'not sure' for the Percocet dosage questions, $74 \%$ of respondents reported believing that the maximum safe dose of different strengths of Percocet was the same. In patients with liver disease, overestimation of the toxicity of acetaminophen may be beneficial for lowering rates of acetaminophen overdose. However, it may also increase the likelihood that these patients will utilize more addictive methods of pain management since pain is such a prevalent and debilitating component of chronic liver disease. ${ }^{48}$

In a study of over 2000 healthcare providers, $40 \%$ of participants reported that they would recommend against any acetaminophen in patients with compensated cirrhosis. ${ }^{49}$ In the same study, physicians were more likely to recommend NSAID than acetaminophen use in patients with underlying liver disease $(p=0.001) .{ }^{49}$ While acetaminophen has been shown to be safe in moderation in patients with liver cirrhosis, NSAIDs are contraindicated in this population due to an established association with nephrotoxicity, gastrointestinal toxicity, and platelet impairment. ${ }^{22-25}$

There is substantial variation in patients' knowledge of what constitutes a safe maximum dose of acetaminophen (Table 4). ${ }^{50-56}$ The variation may be partially explained by different survey formatting. ${ }^{42,43}$ Our survey only listed options in gram amount and the correct answer ( $<4 \mathrm{~g} /$ day) was the highest of the 5 options provided. Additionally, over half our participants responded 'not sure' when asked maximum safe dose of acetaminophen. These responses were coded as incorrect. Some studies provided a similar 'not sure' or 'I don't know' option, ${ }^{42,52,54,55}$ while others did not, ${ }^{43,53}$ but there is no identifiable pattern between these two groups of studies which explains the variability seen. Our study boasts a more diverse patient population than others, but that does not appear to contribute to the variability, as studies measuring lower patient knowledge of Tylenol ${ }^{\circledR}$ were similar in demographics to those which measured higher patient knowledge in this study.

The results of this study provide precedent for further investigating pain management in patients with liver disease. One very important study that would lend clinical significance to these results would be testing acetaminophen knowledge using similar questions in patients who overdose on the drug. Measuring pain scores in patients with liver disease along with medications used and knowledge/perceived safety of acetaminophen will provide evidence for or against a systemic problem of inadequate pain management in liver disease patients due to insufficient education measures by providers about safe and effective analgesia.

Our report has a number of potential limitations. Firstly, data was collected from patients at a single center, and while our study subjects were ethnically diverse, they may not be necessarily representative of the demographics of the nation as a whole. Another potential limitation is that it is difficult to determine whether or not the results of the study are secondary to the answers given by the subjects or secondary to issues related to health literacy among a vulnerable population. However, we wrote the questions at an 8th grade level and tested in a cohort of patients before conducting the survey. The results of our study were consistent with those of similar studies which used comparable wording for their survey but were performed in different populations. ${ }^{51,52}$ Furthermore, both the research assistant and investigator were available if there were questions requiring further clarification.

Underlying liver disease appears to lower the safe consumption threshold of acetaminophen use. ${ }^{20,22,26,27}$ Likewise, the use of alcohol may also affect the safe consumption threshold. ${ }^{28,29,31,57}$ In our study, we did not specifically ask about alcohol use. Given that the threshold is similarly decreased in patients with chronic liver disease and those who habitually consume alcohol, we do not believe omission 
Saab S. et al: Acetaminophen and liver disease

Table 4. Patient and provider ability to correctly identify safe daily dose of acetaminophen

\begin{tabular}{|c|c|c|c|c|}
\hline Population & Cohort & $\begin{array}{l}\text { Total number } \\
\text { of patients }\end{array}$ & $\begin{array}{l}\text { Percentage } \\
\text { identifying correct } \\
\text { safe daily dose }\end{array}$ & First Author Ref \\
\hline \multicolumn{5}{|c|}{ Health care providers } \\
\hline & $\begin{array}{l}\text { Internal medicine family } \\
\text { medicine (Alabama, USA) }\end{array}$ & 76 & $76 \%$ & Hornsby ${ }^{50}$ \\
\hline \multicolumn{5}{|l|}{ Patients } \\
\hline & $\begin{array}{l}\text { Adult general medicine clinic } \\
\text { (Michigan, USA) }\end{array}$ & 104 & $2.0 \%$ & Stumpf ${ }^{51}$ \\
\hline & $\begin{array}{l}\text { Emergency department } \\
\text { (Utah, USA) }\end{array}$ & 1009 & $7 \%$ & Fosnocht ${ }^{52}$ \\
\hline & $\begin{array}{l}\text { Family medicine practice } \\
\text { (Illinois, USA) }\end{array}$ & 102 & $22.5 \%$ & Herndon ${ }^{53}$ \\
\hline & $\begin{array}{l}\text { Emergency department } \\
\text { (France) }\end{array}$ & 500 & $30 \%$ & Boudjemai $^{54}$ \\
\hline & $\begin{array}{l}\text { Outpatient facilities } \\
\text { (Alabama, USA) }\end{array}$ & 284 & $33 \%$ & Hornsby 55 \\
\hline & $\begin{array}{l}\text { Emergency department } \\
\text { (London, UK) }\end{array}$ & 910 & $53.8 \%$ & Wood $^{43}$ \\
\hline & $\begin{array}{l}\text { Emergency department } \\
\text { (New York, USA) }\end{array}$ & 103 & $54 \%$ & Chen $^{42}$ \\
\hline & $\begin{array}{l}\text { Hepatology clinic } \\
\text { (California, USA) }\end{array}$ & 401 & $9.7 \%$ & Our Study \\
\hline
\end{tabular}

of alcohol query is a major limitation of our study. Studies that specifically focus on acetaminophen use in patients who habitually consume alcohol are needed.

We conclude that patients with liver disease have critically low levels of knowledge of acetaminophen, putting them at risk both of acetaminophen overdose, as well as undermedication and inadequate management of chronic pain. We recommend an increase in culturally competent education efforts regarding acetaminophen dosage and its safety in the setting of liver disease. Increasing education in those at risk for low acetaminophen knowledge is essential to minimizing acetaminophen overdose burden and optimizing pain management.

\section{Acknowledgements}

The authors thank Alex Farid, Justin Rheem, MD, and Youssef Challita for assistance in study design, patient recruitment and data analysis.

\section{Conflict of interest}

None

\section{Author contributions}

Study concept and design (SS, PGK, MRV, MAJ), acquisition of data (MRV, WH, VPD, NLE, GC, FAD, MME, SBH, MJT), analysis and interpretation of data (SS, PGK, MRV, MAJ), drafting of the manuscript (SS, PGK, MRV, MAJ), critical revision of the manuscript for important intellectual content (SS, PGK, MRV, $\mathrm{MAJ})$, statistical analysis (JFG), study supervision (SS).

\section{References}

[1] Plaisance KI, Mackowiak PA. Antipyretic therapy: physiologic rationale, diagnostic implications, and clinical consequences. Arch Intern Med 2000;160: 449-456. doi: 10.1001/archinte.160.4.449.

[2] Snow V, Weiss K, Wall EM, Mottur-Pilson C. American Academy of Family Physicians; American College of Physicians-American Society of Internal Medicine. Pharmacologic management of acute attacks of migraine and prevention of migraine headache. Ann Intern Med 2002;137:840-849. doi: 10. 7326/0003-4819-137-10-200211190-00014.

[3] Hochberg MC, Altman RD, April KT, Benkhalti M, Guyatt G, McGowan J, et al. American College of Rheumatology 2012 recommendations for the use of nonpharmacologic and pharmacologic therapies in osteoarthritis of the hand, hip, and knee. Arthritis Care Res (Hoboken) 2012;64:465-474. doi: 10.1002/acr.21596.

[4] Larson AM. Acetaminophen hepatotoxicity. Clin Liver Dis 2007;11:525-548, vi. doi: 10.1016/j.cld.2007.06.006.

[5] Dal Pan G]. Acetaminophen: background and overview. 2009. Available from: http://www.fda.gov/downloads/Advisor.../UCM175767.pdf, accessed June 2016.

[6] Larson AM, Polson J, Fontana RJ, Davern TJ, Lalani E, Hynan LS, et al. Acetaminophen-induced acute liver failure: results of a United States multicenter, prospective study. Hepatology 2005;42:1364-1372. doi: 10.1002/ hep. 20948

[7] Major JM, Zhou EH, Wong HL, Trinidad JP, Pham TM, Mehta H, et al. Trends in rates of acetaminophen-related adverse events in the United States. Pharmacoepidemiol Drug Saf 2016;25:590-598. doi: 10.1002/pds.3906.

[8] Lancaster EM, Hiatt JR, Zarrinpar A. Acetaminophen hepatotoxicity: an updated review. Arch Toxicol 2015;89:193-199. doi: 10.1007/s00204014-1432-2.

[9] Serper M, Wolf MS, Parikh NA, Tillman H, Lee WM, Ganger DR. Risk factors, clinical presentation, and outcomes in overdose with acetaminophen alone or with combination products: results from the acute liver failure study group. ] Clin Gastroenterol 2016:50:85-91. doi: 10.1097/MCG.0000000000000378.

[10] Wolf MS, King J, Jacobson K, Di Francesco L, Bailey SC, Mullen R, et al. Risk of unintentional overdose with non-prescription acetaminophen products. J Gen Intern Med 2012;27:1587-1593. doi: 10.1007/s11606-012-2096-3.

[11] Myers RP, Shaheen AA, Li B, Dean S, Quan H. Impact of liver disease, alcohol abuse, and unintentional ingestions on the outcomes of acetaminophen overdose. Clin Gastroenterol Heptol 2008;6:918-925; quiz 837. doi: 10. 1016/j.cgh.2008.02.053. 
[12] Yoon E, Babar A, Choudhary M, Kutner M, Pyrsopoulos N. Acetaminopheninduced hepatotoxicity: a comprehensive update. J Clin Transl Hepatol 2016; 4:131-142. doi: 10.14218/JCTH.2015.00052.

[13] Schmidt LE, Dalhoff K, Poulsen HE. Acute versus chronic alcohol consumption in acetaminophen-induced hepatotoxicity. Hepatology 2002;35:876-882. doi: 10.1053/jhep.2002.32148.

[14] Nguyen GC, Sam J, Thuluvath PJ. Hepatitis C is a predictor of acute liver injury among hospitalizations for acetaminophen overdose in the United States: a nationwide analysis. Hepatology 2008;48:1336-1341. doi: 10 1002/hep.22536.

[15] Kjartansdottir I, Bergmann OM, Arnadottir RS, Björnsson ES. Paracetamol intoxications: a retrospective population-based study in Iceland. Scand J Gastroenterol 2012;47:1344-1352. doi: 10.3109/00365521.2012.703236.

[16] Iqbal M, Cash WJ, Sarwar S, McCormick PA. Paracetamol overdose: the liver unit perspective. Ir J Med Sci 2012;181:439-443. doi: 10.1007/s11845011-0783-4.

[17] U.S. Department of Health and Human Services, National Institutes of Health, National Institute of Diabetes and Digestive and Kidney Diseases, Subcommittee of the Digestive Diseases Interagency Coordinating Committee. Action plan for liver disease research. 2004 (NIH Publication No. 04-5491). Available from http://www2.niddk.nih.gov/NR/rdonlyres/ 37A98A02-9631-431A-8C30-3F2D1B1945A2/0/ldrb_cover_toc.pdf.

[18] Verbeeck RK. Pharmacokinetics and dosage adjustment in patients with hepatic dysfunction. Eur J Clin Pharmacol 2008;64:1147-1161. doi: 10. 1007/s00228-008-0553-z.

[19] Delcò F, Tchambaz L, Schlienger R, Drewe J, Krähenbühl S. Dose adjustment in patients with liver disease. Drug Saf 2005;28:529-545. doi: 10.2165/ 00002018-200528060-00005.

[20] Imani F, Motavaf M, Safari S, Alavian SM. The therapeutic use of analgesics in patients with liver cirrhosis: a literature review and evidence-based recommendations. Hepat Mon 2014;14:e23539. doi: 10.5812/hepatmon.23539.

[21] Hayward KL, Powell EE, Irvine KM, Martin JH. Can paracetamol (acetaminophen) be administered to patients with liver impairment? $\mathrm{Br} J$ Clin Pharmacol 2016;81:210-222. doi: 10.1111/bcp.12802.

[22] Benson GD, Koff RS, Tolman KG. The therapeutic use of acetaminophen in patients with liver disease. Am J Ther 2005;12:133-141. doi: 10.1097/01. mjt.0000140216.40700.95.

[23] Laffi G, La Villa G, Pinzani M, Marra F, Gentilini P. Arachidonic acid derivatives and renal function in liver cirrhosis. Semin Nephrol 1997;17:530-548.

[24] Lee YC, Chang CH, Lin JW, Chen HC, Lin MS, Lai MS. Non-steroidal antiinflammatory drugs use and risk of upper gastrointestinal adverse events in cirrhotic patients. Liver Int 2012;32:859-866. doi: $10.1111 / j .1478$ 3231.2011.02739.x

[25] De Lédinghen $V$, Heresbach $D$, Fourdan O, Bernard $P$, Liebaert-Bories MP, Nousbaum JB, et al. Anti-inflammatory drugs and variceal bleeding: a case-control study. Gut 1999;44:270-273. doi: 10.1136/gut.44.2.270.

[26] American Liver Foundation. The American Liver Foundation Issues Warning on Dangers of Excess Acetaminophen. American Liver Foundation. 2006. Available from: http://www.liverfoundation.org/downloads/alf_download_ 39.pdf, assessed June 2016

[27] Riley TR, Smith JP. Preventive care in chronic liver disease. J Gen Intern Med 1999;14:699-704. doi: 10.1046/j.1525-1497.1999.11188.x.

[28] Kuffner EK, Dart RC, Bogdan GM, Hill RE, Casper E, Darton L. Effect of maximal daily doses of acetaminophen on the liver of alcoholic patients: a randomized, double-blind, placebo-controlled trial. Arch Intern Med 2001; 161:2247-2252. doi: 10.1001/archinte.161.18.2247.

[29] Dart RC, Green JL, Kuffner EK, Heard K, Sproule B, Brands B. The effects of paracetamol (acetaminophen) on hepatic tests in patients who chronically abuse alcohol - a randomized study. Aliment Pharmacol Ther 2010;32: 478-486. doi: 10.1111/j.1365-2036.2010.04364.x.

[30] Bartels S, Sivilotti M, Crosby D, Richard J. Are recommended doses of acetaminophen hepatotoxic for recently abstinent alcoholics? A randomized trial. Clin Toxicol (Phila) 2008;46:243-249. doi: 10.1080/15563650701447020.

[31] Kuffner EK, Green JL, Bogdan GM, Knox PC, Palmer RB, Heard K, et al. The effect of acetaminophen (four grams a day for three consecutive days) on hepatic tests in alcoholic patients-a multicenter randomized study. BMC Med 2007;5:13. doi: 10.1186/1741-7015-5-13.

[32] Khalid SK, Lane J, Navarro V, Garcia-Tsao G. Use of over-the-counter analgesics is not associated with acute decompensation in patients with cirrhosis. Clin Gastroenterol Hepatol 2009;7:994-999; quiz 913-914. doi: 10.1016/j. cgh.2009.04.015.

[33] Heard K, Green JL, Bailey JE, Bogdan GM, Dart RC. A randomized trial to determine the change in alanine aminotransferase during 10 days of paracetamol (acetaminophen) administration in subjects who consume moderate amounts of alcohol. Aliment Pharmacol Ther 2007;26:283-290. doi: 10. 1111/j.1365-2036.2007.03368.x.

[34] Food and Drug Administration, HHS. Organ-specific warnings; internal analgesic, antipyretic, and antirheumatic drug products for over-the-counter human use; final monograph. Final rule. Fed Regist 2009;74:19385-19409.
[35] Norco 7-5 mg_325 mg and 10 mg_325 mg, Food and Drug Administration. 2014. Available from: http://www.accessdata.fda.gov/drugsatfda_docs/label/ 2014/040148s053lbl.pdf, accessed June 2016.

[36] Official site of Vicodin ${ }^{\circledR}$ (hydrocodone bitartrate and acetaminophen) tablets, USP. Available from: https://www.vicodin.com/hcp, accessed June 2016.

[37] TYLENOL ${ }^{\circledR}$ with Codeine, Food and Drug Administration, 2014. Available from: https://www.drugs.com/pro/Tylenol@-with-codeine.html, accessed June 2016.

[38] PERCOCET ${ }^{\circledR}$ (Oxycodone and Acetaminophen tablets, USP), Food and Drug Administration, 2006.

[39] Jacobson HE, Hund L, Soto Mas F. Predictors of English Health Literacy among U.S. Hispanic Immigrants: The importance of language, bilingualism and sociolinguistic environment. Lit Numer Stud 2016;24:43-64. doi: 10. 5130/Ins.v24i1.4900.

[40] Berkman ND, Sheridan SL, Donahue KE, Halpern DJ, Crotty K. Low health literacy and health outcomes: an updated systematic review. Ann Intern Med 2011:155:97-107. doi: 10.7326/0003-4819-155-2-201107190-00005.

[41] Lee HY, Lee J, Kim NK. Gender differences in health literacy among Korean adults: do women have a higher level of health literacy than men? Am J Mens Health 2015;9:370-379. doi: 10.1177/1557988314545485.

[42] Chen L, Schneider S, Wax P. Knowledge about acetaminophen toxicity among emergency department visitors. Vet Hum Toxicol 2002;44:370-373.

[43] Wood DM, English E, Butt S, Ovaska H, Garnham F, Dargan PI. Patient knowledge of the paracetamol content of over-the-counter (OTC) analgesics, cough/cold remedies and prescription medications. Emerg Med J 2010;27: 829-833. doi: 10.1136/emj.2009.085027.

[44] Les I, Doval E, Flavià M, Jacas C, Cárdenas G, Esteban R, et al. Quality of life in cirrhosis is related to potentially treatable factors. Eur J Gastroenterol Hepatol 2010;22:221-227. doi: 10.1097/MEG.0b013e3283319975.

[45] Schäfer G, Prkachin KM, Kaseweter KA, Williams AC. Health care providers' judgments in chronic pain: the influence of gender and trustworthiness. Pain 2016;157:1618-1625. doi: 10.1097/j.pain.0000000000000536.

[46] Richardson A, Allen JA, Xiao H, Vallone D. Effects of race/ethnicity and socioeconomic status on health information-seeking, confidence, and trust. J Health Care Poor Underserved 2012;23:1477-1493. doi: 10.1353/hpu. 2012.0181.

[47] Clayman ML, Manganello JA, Viswanath K, Hesse BW, Arora NK. Providing health messages to Hispanics/Latinos: understanding the importance of language, trust in health information sources, and media use. J Health Commun 2010;15 Suppl 3:252-263. doi: 10.1080/10810730.2010.522697.

[48] Marchesini G, Bianchi G, Amodio P, Salerno F, Merli M, Panella C, et al. Factors associated with poor health-related quality of life of patients with cirrhosis. Gastroenterology 2001;120:170-178. doi: 10.1053/gast.2001.21193.

[49] Rossi S, Assis DN, Awsare M, Brunner M, Skole K, Rai J, et al. Use of overthe-counter analgesics in patients with chronic liver disease: physicians' recommendations. Drug Saf 2008;31:261-270. doi: 10.2165/00002018200831030-00007.

[50] Hornsby LB, Przybylowicz ], Andrus M, Starr J. Survey of physician knowledge and counseling practices regarding acetaminophen. J Patient Saf 2010; 6:216-220. doi: 10.1097/PTS.0b013e3181fca8b4.

[51] Stumpf JL, Skyles AJ, Alaniz C, Erickson SR. Knowledge of appropriate acetaminophen doses and potential toxicities in an adult clinic population. J Am Pharm Assoc (2003) 2007;47:35-41. doi: 10.1331/1544-3191.47.1.35. Stumpf.

[52] Fosnocht D, Taylor JR, Caravati EM. Emergency department patient knowledge concerning acetaminophen (paracetamol) in over-the-counter and prescription analgesics. Emerg Med J 2008;25:213-216. doi: 10.1136/emj. 2007.053850.

[53] Herndon CM, Dankenbring DM. Patient perception and knowledge of acetaminophen in a large family medicine service. J Pain Palliat Care Pharmacother 2014;28:109-116. doi: 10.3109/15360288.2014.908993.

[54] Boudjemai Y, Mbida P, Potinet-Pagliaroli V, Géffard F, Leboucher G, Brazier JL, et al. Patients' knowledge about paracetamol (acetaminophen): a study in a French hospital emergency department. Ann Pharm Fr 2013;71:260-267. doi: 10.1016/j.pharma.2013.03.001.

[55] Hornsby LB, Whitley HP, Hester EK, Thompson M, Donaldson A. Survey of patient knowledge related to acetaminophen recognition, dosing, and toxicity. J Am Pharm Assoc (2003) 2010;50:485-489. doi: 10.1331/JAPhA.2010. 08175.

[56] Ip EJ, Tang TT, Cheng V, Yu J, Cheongsiatmoy DS. Impact of educational levels and health literacy on community acetaminophen knowledge. J Pharm Pract 2015;28:499-503. doi: 10.1177/0897190014544819.

[57] Dart RC, Kuffner EK, Rumack BH. Treatment of pain or fever with paracetamol (acetaminophen) in the alcoholic patient: a systematic review. Am J Ther 2000;7:123-134. doi: 10.1097/00045391-200007020-00009. 